\title{
Analysing teacher knowledge for technology education in primary schools
}

\author{
Ellen J. Rohaan • Ruurd Taconis • Wim M. G. Jochems
}

Published online: 4 December 2010

(C) The Author(s) 2010. This article is published with open access at Springerlink.com

\begin{abstract}
Teacher knowledge guides a teacher's behaviour in the classroom. Teacher knowledge for technology education is generally assumed to play an important role in affecting pupils' learning in technology. There are an abundant number of teacher knowledge models that visualise different domains of teacher knowledge, but clear empirical evidence on how these domains interact is lacking. Insights into the interaction of teacher knowledge domains could be useful for teacher training. In this study, the hypothesised relations between different domains of teacher knowledge for technology education in primary schools were empirically investigated. Subject matter knowledge, pedagogical content knowledge, attitude, and self-efficacy were measured with tests and questionnaires. Results from a path analysis showed that subject matter knowledge is an important prerequisite for both pedagogical content knowledge and self-efficacy. Subsequently, teachers' self-efficacy was found to have a strong influence on teachers' attitude towards technology. Based on the findings in this study, it is recommended that teacher training should first of all focus on the development of teachers' subject matter knowledge and pedagogical content knowledge. This knowledge will positively affect teachers' confidence in teaching and, in turn, their attitude towards the subject. More confidence in technology teaching and a more positive attitude are expected to increase the frequency of technology education, which consequently increases teaching experience and thereby stimulates the development of teachers' pedagogical content knowledge. This circle of positive reinforcement will eventually contribute to the quality of technology education in primary schools.
\end{abstract}

Keywords Teacher knowledge $\cdot$ Pedagogical content knowledge $\cdot$ Subject matter knowledge $\cdot$ Attitude towards technology $\cdot$ Self-efficacy $\cdot$ Technology education

E. J. Rohaan $(\bowtie) \cdot$ R. Taconis · W. M. G. Jochems

Eindhoven School of Education, Eindhoven University of Technology,

P.O. Box 513, MB 5600 Eindhoven, The Netherlands

e-mail: ellen.rohaan@esoe.nl 


\section{Introduction}

Primary school (K-6) technology education in The Netherlands is part of an integrative learning domain called 'natuur en techniek' (nature and technology), which was introduced around the year 2000, but is structurally implemented in only a small number of curricula. For the entire learning domain, seven standards are formulated, two of which are specifically concerned with technology education: (1) pupils learn to find connections between the functioning, design, and use of materials of products in their own environment, and (2) pupils learn to design, realise, and evaluate solutions for technical problems (Greven and Letschert 2006). Because these standards are formulated in a rather general way, a governmentally approved framework of key learning areas is not available, and because new textbooks and learning materials are not yet purchased by most schools, it is often the teachers themselves who decide what and how technology is taught in the classrooms. However, most primary school teachers in The Netherlands have not received any training in teaching technology and their affinity with technology is often low.

When high quality technology education is aimed for, high quality technology teachers are required. But what do primary school teachers need to know in order to become high quality technology teachers? And what are the cognitions and beliefs that underlie teachers' behaviour during technology activities? To answer these questions, one needs to study the concept of teacher knowledge, which can be defined as "the whole of knowledge and insights that underlie teachers' actions in practice" (Verloop et al. 2001, p. 446). Teacher knowledge guides a teacher's behaviour in the classroom. It is personal knowledge that is acquired through experiences in his (or her) own teaching practice. Besides, it is partly tacit knowledge, which implies that a teacher is unable to articulate part of his acquired teacher knowledge. Furthermore, teacher knowledge is integrated knowledge, consisting of scientific as well as non-scientific elements. Beliefs are closely interwoven and play an important role in constructing and organising teacher knowledge (Van Driel et al. 2001). Various other terms have been used to describe the concept of teacher knowledge, e.g., 'craft knowledge' (Grimmett and MacKinnon 1992) and 'practical knowledge' (Van Driel et al. 2001).

Grossman (1990) designed a model of teacher knowledge with four knowledge domains: (1) subject matter knowledge (SMK) (2) general pedagogical knowledge (3) knowledge of the context, and (4) pedagogical content knowledge (PCK). In this model, PCK is presented as the central domain, which reciprocally interacts with the other domains. Opposed to this so-called 'transformative model', in which PCK is a transformation of different knowledge domains into a new and unique domain, the integrative model' does not present PCK as a knowledge domain on its own. In the integrative model teaching is seen as an act of integrating knowledge of the subject, pedagogy, and context (Gess-Newsome and Lederman 1999). Despite of the strong simplification of reality, both of these structural models are useful when studying teacher knowledge. The transformative model of teacher knowledge reflects the position of this study.

The presented study focuses on technology-specific teacher knowledge. That is, only knowledge domains that are specific for technology education were included. Three domains of teacher knowledge were defined for the purpose of this study: (A) SMK (B) PCK, and (C) attitude and self-efficacy (the affective domain). SMK is knowledge about the content that is to be taught. This knowledge domain contains conceptual and procedural knowledge, on the one hand, and understanding of the nature of the subject, on the other (Grossman 1990). Conceptual knowledge is knowledge of facts, principles, and theories. This includes knowledge about technological concepts, e.g., energy and power, 
constructions, transportation, ICT, and electronics. Procedural knowledge of technology is mainly concerned with knowledge to solve technological design problems (Garmire and Pearson 2006), but also includes determining and controlling, utilising, and assessing impacts of technology (ITEA 2006). Understanding the nature of the subject has to do with teachers' concept or perception of technology education and includes, e.g., understanding the differences between the learning objectives of science education and technology education.

PCK is conceptualised in many different ways by various researchers (Van Driel et al. 1998). For the present study, three basic knowledge components of PCK for technology education in primary schools were formulated: (1) knowledge of pupils' concept of technology and knowledge of their pre- and misconceptions related to technology (2) knowledge of the nature and purpose of technology education, and (3) knowledge of pedagogical approaches and teaching strategies for technology education (Rohaan et al. 2010). Most researchers assume SMK to be a prerequisite for the development of PCK (Van Driel et al. 1998). Besides, it is supposed that the components of PCK function as a whole and an effective teacher needs to have knowledge of every PCK component (Magnusson et al. 1999). It should also be taken into account that the development of PCK in primary school teachers may differ from secondary school teachers, because they usually do not specialise in a specific subject area. Therefore, they may not develop specific PCK for all different subjects and topics they teach, but instead develop PCK on a more general level (Appleton 2008).

Attitude towards technology and self-efficacy in teaching technology form the affective domain of teacher knowledge in this study. It is generally agreed upon that one's attitude "represents a summary evaluation of a psychological object captured in such attribute dimensions as good-bad, harmful-beneficial, pleasant-unpleasant, and likable-dislikable" (Ajzen 2001, p. 28). Attitudes are influenced by cognition as well as by affect. Hence, teachers' attitude towards technology is affected by their concept of technology and their feelings about technology. Teachers' beliefs about their ability to enact effective teaching methods for specific teaching goals (i.e., self-efficacy or confidence in teaching), was proposed to be an affective affiliate of PCK (Park and Oliver 2008). Confidence in teaching science was assumed to be an important condition for the development of science PCK of primary school teachers (Appleton 2008). Besides, teachers usually spend less time on subject areas in which their perceived self-efficacy was low (Mulholland and Wallace 2001). In a study that aimed to broaden pre-service teachers' perceptions of technology by engagement in a technology unit of study, many teachers reported they had achieved enough confidence and capability to teach technology in primary schools (McRobbie et al. 2000). This implies that enhanced knowledge of the subject is related to enhanced confidence in teaching the subject. However, in another study it was concluded that confidence in teaching not necessarily results from SMK or PCK (Johnston and Ahtee 2006).

Briefly stated, clear empirical evidence on how different domains of teacher knowledge interact is still lacking. Insights into the interaction of teacher knowledge domains could be useful in order to design effective programmes for teacher training in technology education. In this study, it is empirically investigated how three different domains of technologyspecific teacher knowledge (i.e., SMK, PCK, attitude and self-efficacy) are interrelated. As concluded earlier in a literature review (Rohaan et al. 2010), teacher knowledge is found to affect teaching and, in turn, is supposed to affect pupils' concept of and attitude towards technology. Moreover, it is assumed that teachers' SMK positively affects their pupils' concept and that teachers' attitude positively affects their pupils' attitude. Besides, teachers' PCK is hypothesised to affect both pupils' concept and attitude. However, 
investigation of the hypothesised relations between teacher and pupil variables are beyond the scope of this article. In Fig. 1 all hypothesised relations are schematically presented. Path analysis was used to test the hypotheses concerning teacher knowledge.

In the next section, the methodology, which includes the instruments, participants, and procedure, of this study is described. Thereafter, the results are reported an in the concluding section, an answer to the research question is formulated, and the study is critically discussed.

\section{Methodology}

Instruments

To measure teachers' PCK of technology education, the Teaching of Technology Test (TTT) was used. The TTT was specifically constructed to use in this study, because existing PCK instruments were not suitable for the quantitative nature of this study. The test construction and validation is reported in a previous published article (Rohaan et al. 2009). The TTT contains 18 multiple choice items with four answer alternatives, which can be characterised as representing 'high PCK', 'low PCK', pedagogical knowledge, and content knowledge ('no PCK'). The test consists of three sub scales that represent the three predefined knowledge components of PCK: (1) knowledge of pupils' general concept and misconceptions related to technology (2) knowledge of the nature and purpose of technology education, and (3) knowledge of pedagogical approaches and teaching strategies for technology education. The items involve different phases of technology class situations (preparation, instruction and communication, and assessment) and vary on technological topics (electricity, constructions, mechanic transmissions, and applied physics). Test-retest reliability was chosen as an alternative measure for consistency of the test, because of the heterogeneous nature of PCK. Pearson's correlation coefficient was found to be 0.622 $(\mathrm{n}=31)$, which means that the test is moderately reliable over time.

Teachers' SMK of technology was measured with the Cito technology test (Weerden et al. 2003) This test measures conceptual knowledge of technology and is originally designed to use with primary school pupils in the end of the sixth grade (12-year-olds), but

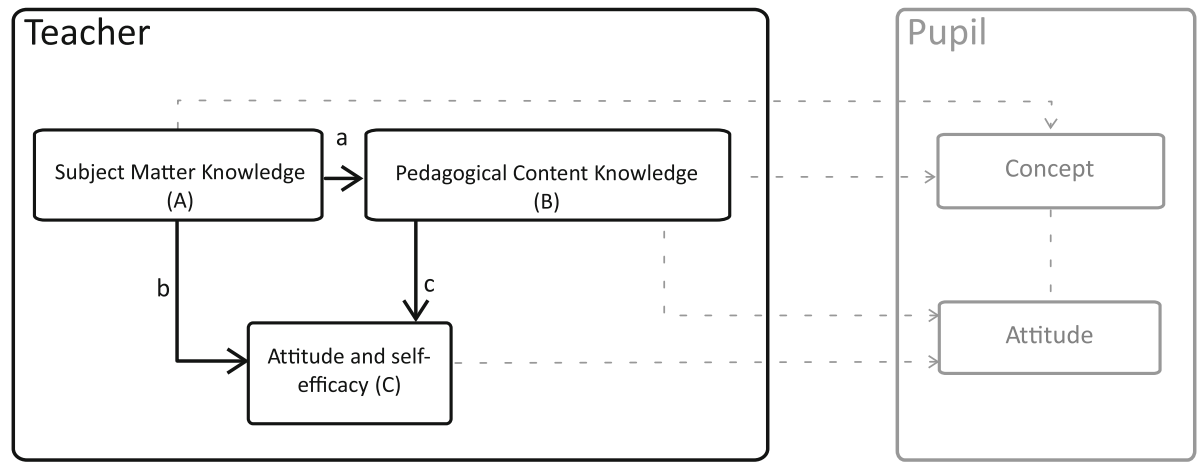

Fig. 1 Schematic representation of the hypothetical relations between teacher knowledge (left) and pupils' concept and attitude (right). The solid black arrows represent the relations between teacher knowledge domains that are analysed in this study 
turned out to be useful as well with the present sample of primary school teachers. Furthermore, it accurately reflects the content of technology education in Dutch primary schools, because it was especially designed for this context. The Cito technology test is a multiple choice test that contains 48 items with 3-4 answer alternatives. Reliability in terms of Cronbach's alpha was found to be 0.79 in the sample of the present study $(\mathrm{n}=361)$.

The Personal Science Teaching Efficacy Belief (PSTE) scale of the Science Teaching Efficacy Belief Instrument (STEBI) was used to measure self-efficacy in technology teaching. We adapted the STEBI from Bleicher (2004), which is a modification from the original by Enochs and Riggs (1990), translated it into Dutch and slightly revised it to fit to the context of technology education in primary schools. This instrument is often used in other scientific studies and has proven its validity in several research contexts. The PSTE scale contains 13 items with a 5-point Likert scale. Reliability in terms of Cronbach's alpha was found to be 0.91 in the present sample $(n=354)$.

With the VTB attitude instrument (Walma van der Molen et al. 2007) teachers' attitude towards technology was measured. The instrument consists of a science and technology scale, of which only the technology scale was used in this study. This instrument is recently designed for the Dutch school context. The technology scale has 18 items distributed over five sub scales (gender issues, societal relevance, interest, future intentions, and difficulty) and makes use of a 4-point Likert scale. Reliability in terms of Cronbach's alpha was found to be 0.85 in the present sample $(n=356)$.

In Table 1 an overview of the instruments that are used in this study is provided. All instruments were administered through the online questionnaire system CORF (http:// www.corfstart.nl). For statistical analysis of the data the software packages SPSS 16.0 and Mplus 5.1 were used.

\section{Participants}

Participants were recruited through a letter send by mail and, as a reminder, by email to the directive board of all primary schools in The Netherlands (nearly 7.000 schools). Teachers from the upper grades (3-6) and their pupils were asked to participate voluntarily. In order to stimulate participation, 10 annual season tickets for a science centre of choice were given away at random.

The teachers sample consisted of 354 primary school teachers $(61.6 \%$ female and $38.4 \%$ male) in The Netherlands. Their mean age was 42.5 years $(\mathrm{SD}=12.0)$, their mean years of teaching experience 17.6 years $(\mathrm{SD}=12.1)$, and their mean years of technology teaching experience 4.3 years $(\mathrm{SD}=6.7)$. For these variables, the sample is representative for the population of primary school teachers in The Netherlands. Most teachers $(91.4 \%)$

Table 1 Overview of instruments used in this study

\begin{tabular}{llll}
\hline Variable & Instrument & Reliability & References \\
\hline PCK & TTT & $0.622^{\mathrm{a}}$ & Rohaan et al. (2009) \\
SMK & Cito & $0.79^{\mathrm{b}}$ & Weerden et al. (2003) \\
Self-efficacy & STEBI (PSTE) & $0.91^{\mathrm{b}}$ & Bleicher (2004) \\
Attitude & VTB & $0.85^{\mathrm{b}}$ & Walma van der Molen et al. (2007) \\
\hline
\end{tabular}

\footnotetext{
a Pearson correlation coefficient (consistency over time)

b Cronbach's alpha (internal consistency)
} 
taught in the upper grades (3-6) of primary education. A refresher course in technology education was completed by $26.3 \%$ of the teachers in the sample.

\section{Procedure}

The data analysis was performed in several stages. First, empty and duplicate cases were removed from the data files. A descriptive analysis was done in order to check the sample characteristics. Before calculating the test scores, negative formulated items were recoded. After recoding, test scores (means and standard deviations) were calculated and checked on being normally distributed.

Reliability (internal consistency) of the instruments, and their sub scales, was analysed by calculating Cronbach's alpha. Additionally, for the TTT, test-retest reliability (stability over time) was calculated by correlating the test scores of two consecutive administrations in one group of teachers $(\mathrm{n}=31)$. Subsequently, Pearson product-moment correlations between test scores were computed in order to explore the relations between the measured variables.

In order to uncover the causal relations between the different teacher knowledge domains a path model was defined and tested as follows. Self-efficacy was hypothesised to be affected by SMK and PCK. PCK would be affected by SMK, and attitude was assumed to be affected by SMK and self-efficacy. With reference to the diagram showing the hypothetical relations (Fig. 1), this path model concerned the relations (a) SMK with PCK, (b) SMK with attitude and self-efficacy, and (c) PCK with self-efficacy. Moreover, between self-efficacy and attitude, the two components of the affective domain, a relation from self-efficacy to attitude was hypothesised. Hence, the relation between PCK and attitude was supposed to be mediated by self-efficacy.

\section{Results}

Table 2 presents the mean test scores, standard deviations, and Pearson product-moment correlations for the variables used in the path model of teacher knowledge domains. Teachers' PCK of technology education ranged from 2.8 to 8.6 on a scale from 0 to 10 . The mean score was $5.8(\mathrm{SD}=1.1)$, which implies that, on average, primary school teachers had poor to mediocre levels of PCK in technology education. Furthermore, they averaged rather high on SMK with a mean score of $8.0(\mathrm{SD}=1.0)$ and a score range from 3.1 to 9.8 (scale 0-10). It has to be noticed, that the SMK test was originally constructed for 6-graders (age 11-12) and could be indicated as easy for primary school teachers.

Table 2 Mean test scores, standard deviations, and correlations of variables in the path model of teacher knowledge domains $(\mathrm{n}=354)$

\begin{tabular}{lrlllll}
\hline Variable & Mean & SD & PCK & SMK & SEF & ATT \\
\hline PCK & 5.8 & 1.1 & - & & & \\
SMK & 8.0 & 1.0 & $0.184^{* *}$ & - & & \\
SEF & 45.4 & 8.5 & $0.153^{* *}$ & $0.372^{* *}$ & - & \\
ATT & 52.6 & 7.1 & $0.122^{*}$ & $0.365^{* *}$ & $0.594^{* *}$ & - \\
\hline
\end{tabular}

$P C K$ pedagogical content knowledge, SMK subject matter knowledge, SEF self-efficacy, ATT attitude

$* p<0.05 ; * * p<0.01$ 
Fig. 2 Path model of teacher knowledge domains with standardised path coefficients

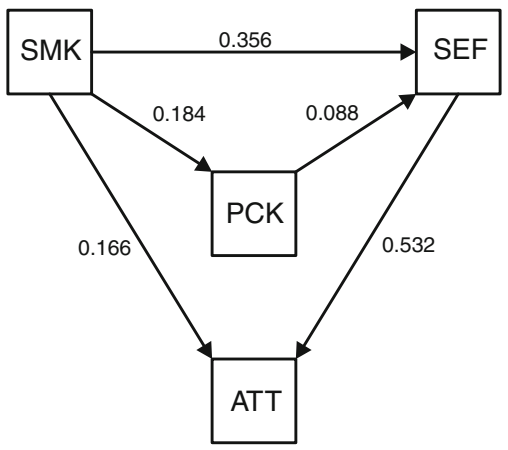

On the self-efficacy in technology teaching scale, scores ranged from 17.0 to 64.0 and the mean score was $45.4(\mathrm{SD}=8.5)$. A mean score per item of 3.5 on the 5-point Likert scale suggested that, on average, teachers were moderately confident in teaching technology. Teachers' attitude towards technology had a mean score of $52.6(\mathrm{SD}=7.1)$ with a score range from 23.0 to 71.0. A mean score per item of 2.9 on the 4-point Likert scale indicated that, on average, teachers had a more positive than negative attitude.

All correlations between the variables of teacher knowledge were statistically significant. The magnitudes varied from small (0.122) to large (0.594). Small size correlations were found between PCK and SMK, PCK and self-efficacy, and PCK and attitude. Medium size correlations were found between SMK and self-efficacy, and SMK and attitude. A large correlation was found between self-efficacy and attitude.

Figure 2 illustrates the path model of teacher knowledge domains with all standardised path coefficients. According to commonly used fit indices (Schermelleh-Engel et al. 2003), a non-significant $p$-value of the Chi-square test (0.8191), a CFI and TLI that were larger than 0.95 (respectively, 1.000 and 1.025), and a RMSEA and SRMR smaller than 0.05 (respectively, 0.000 and 0.003 ), the fit of this model was very close. All paths in the model showed significant effects, except for the path from PCK to self-efficacy. However, when assuming all measurements to be perfectly reliable in terms of internal consistency, i.e., correcting for attenuation, this path had a standardised estimate of 0.355 . Moreover, with attenuation correction, the path coefficient of the path from SMK to PCK became a large direct effect of 0.624 . All paths were positively related, as hypothesised.

The significant path coefficients varied from small (0.166) to large (0.532). The total effect of SMK on self-efficacy was found to be a medium effect of 0.372 $(0.356+(0.184 * 0.088))$ and the total effect of SMK on attitude was found to be a medium effect of $0.355(0.166+(0.356 * 0.532))$. Table 3 provides all path coefficients, $p$-values, and explained variances of this path model. The variance of attitude was explained for $37.6 \%$ by self-efficacy and SMK. The variance of self-efficacy was explained for $14.6 \%$ by SMK and PCK. For PCK, only 3.4\% of the variance was explained by SMK in this model.

\section{Conclusions and discussion}

The purpose of this study was to investigate domains of teacher knowledge for technology education in primary schools and their interrelationships. Based on analysis of the various test scores, we conclude that primary school teachers have a basic level of SMK but an insufficient level of PCK regarding technology education. This finding is not unexpected, 
Table 3 Standardised path coefficients, $p$-values, and explained variances $\left(\mathrm{R}^{2}\right)$ from path model of teacher knowledge domains

\begin{tabular}{llll}
\hline Effect & Estimate & $p$ & $\mathrm{R}^{2}$ \\
\hline On ATT & & & 0.376 \\
Of SEF & 0.532 & 0.000 & \\
Of SMK & 0.166 & 0.000 & 0.146 \\
On SEF & & & \\
Of SMK & 0.356 & 0.000 & 0.034 \\
Of PCK & 0.088 & $0.078(\mathrm{~ns})$ & \\
On PCK & & & 0.000 \\
Of SMK & 0.184 & & \\
\hline
\end{tabular}

$P C K$ pedagogical content knowledge, SMK subject matter knowledge, SEF self-efficacy, ATT attitude

Moreover, the frequency of technology activities, scored on a 5-point scale from never to more than once a week, was significantly and positively correlated with teachers' attitude $\left(\mathrm{r}_{\mathrm{s}}=0.298, p<0.01\right)$ and selfefficacy $\left(\mathrm{r}_{\mathrm{s}}=0.336, p<0.01\right)$

because science and technology education is a relatively new learning domain in Dutch primary schools. Although technology education today is part of the compulsory learning goals in primary education, it is structurally implemented in the curricula of only a small number (about 20\%) of all primary schools in The Netherlands. Most schools offer technology lessons only infrequently and on a non-regular basis. Besides, technology education is neither structurally implemented in all primary teacher training institutes. In other words, technology education did not yet develop into an established learning domain. Technology education is not clearly defined and is lacking an explicit structural framework including key learning concepts, suggestions for the sequence of learning activities (in relation to pupils' cognitive development), and detailed standards. Consequently, most teachers did not yet develop profound teacher knowledge in this field, which is also reflected in a high variety of perceptions of technology education among primary school teachers. Fortunately, primary teachers do have a reasonable amount of confidence in teaching technology and a rather positive attitude towards technology, which provides a good starting point for learning.

From the path analysis of teacher knowledge domains, we conclude that SMK is an important influencing factor for PCK as well as for self-efficacy. In turn, self-efficacy has a strong effect on teachers' attitude towards technology. Furthermore, the positive correlations between teachers' confidence (self-efficacy) and attitude on the one hand, with the frequency of technology activities on the other, suggest that the enhancement of teachers' confidence in technology teaching and/or attitude towards technology will increase the frequency of technology activities. Subsequently, more experience in teaching technology will stimulate the development of teachers' PCK, which will again lead to more confidence in teaching, a more positive attitude, and etcetera. This circle of positive reinforcement will eventually contribute to the quality of technology education in primary schools.

Critical remarks can be made when reflecting on the methodology used in the presented study. In the first place, participation in the study was voluntary. Although the sample size was considerably large and the demographics, such as age, gender, and denomination of the schools, were representative for the population of primary school teachers in The Netherlands, the sample might have been biased in terms of knowledge of and affinity with technology education. It is likely that teachers with relatively more knowledge and higher 
affinity were over-represented in the sample. Because of the absence of large scale data on teacher knowledge and affinity regarding technology education in primary schools, this potential bias in the sample could not be verified. On the other hand, a biased sample with respect to teacher knowledge can also be interpreted as an advantage. The variance in test scores on the PCK and SMK tests was large enough to carry out statistical analyses, which could have been problematic when teacher knowledge levels were very low. Put it simple, if teacher knowledge would have been nearly absent in the sample, hardly anything could have been measured.

Lessons for educational practice can be learned from the findings in this study. Regarding pre-service and in-service teacher training in technology education, it is recommended to focus on acquiring and developing SMK as well as PCK. Teachers should be stimulated to acquire relevant SMK and, above all, should be trained to use their SMK to foster pupils' learning in technology, in other words, to develop their PCK. This implies that teachers should become familiar with pedagogical approaches that are suitable for technology education, e.g., inquiry-based and problem-based learning. Moreover, they should be made aware of the nature, purpose, and characteristics of technology education. It also implies that they should learn to ask provoking questions, use powerful analogies, explain the subject matter in various ways, and recognise common misconceptions. Most time should be spent on hands-on technology activities ('teach what you preach'). Actually doing and experiencing technology education is expected to most effectively increase teachers' confidence in teaching technology themselves. In the end, more profound knowledge of teaching technology will help teachers to recognise the added value of high quality technology education. Still, an important question remains unanswered. To what extent does teacher knowledge affect pupils?

Open Access This article is distributed under the terms of the Creative Commons Attribution Noncommercial License which permits any noncommercial use, distribution, and reproduction in any medium, provided the original author(s) and source are credited.

\section{References}

Ajzen, I. (2001). Nature and operation of attitudes. Annual Review of Psychology, 52(2), 27-58.

Appleton, K. (2008). Developing science pedagogical content knowledge through mentoring elementary teachers. Journal of Science Teacher Education, 19(6), 523-545.

Bleicher, R. E. (2004). Revisiting the STEBI B: Measuring self-efficacy in preservice elementary teachers. School Science and Mathematics, 104(8), 1-10.

Enochs, L. G., \& Riggs, I. M. (1990). Further development of an elementary science teaching efficacy belief instrument: A preservice elementary scale. Paper presented at the Annual Meeting of the National Association Research in Science Teaching, Atlanta, April 8-11, 1990.

Garmire, E., \& Pearson, G. (2006). Tech tally. Approaches to assessing technological literacy. Washington, DC: National Academy of Engineering and National Research Council.

Gess-Newsome, J., \& Lederman, N. G. (Eds.). (1999). Examining pedagogical content knowledge. The construct and its implications for science education. Science \& technology education library (Vol. 6). Dordrecht, Boston, London: Kluwer.

Greven, J., \& Letschert, J. (2006). Kerndoelenboekje. [Booklet of standards]. Den Haag: DeltaHage.

Grimmett, P. P., \& MacKinnon, A. M. (1992). Craft knowledge and the education of teachers. In G. Grant (Ed.), Review of research in education (Vol. 18, pp. 385-456). Washington, DC: American Educational Research Association (AERA).

Grossman, P. L. (1990). The making of a teacher: Teacher knowledge and teacher education. New York: Teachers College Press, Columbia University.

ITEA (Ed.). (2006). Technological literacy for all. A rationale and structure for the study of technology (2nd ed.). Reston: International Technology Education Association (ITEA). 
Johnston, J., \& Ahtee, M. (2006). Comparing primary student teachers' attitudes, subject knowledge and pedagogical content knowledge needs in a physics activity. Teaching and Teacher Education, 22(4), 503-512.

Magnusson, S., Krajcik, J., \& Borko, H. (1999). Nature, sources, and development of pedagogical content knowledge for science teaching. In J. Gess-Newsome \& N. G. Lederman (Eds.), Examining pedagogical content knowledge. The construct and its implications for science education (Vol. 6, pp. 95-132). Dordrecht, Boston, London: Kluwer.

McRobbie, C. J., Ginns, I. A., \& Stein, S. J. (2000). Preservice primary teachers' thinking about technology and technology education. International Journal of Technology and Design Education, 10(1), 81-101.

Mulholland, J., \& Wallace, J. (2001). Teacher induction and elementary science teaching: Enhancing selfefficacy. Teaching and Teacher Education, 17(2), 243-261.

Park, S., \& Oliver, J. S. (2008). Revisiting the conceptualization of pedagogical content knowledge (PCK): PCK as a conceptual tool to understand teachers as professionals. Research in Science Education, 38(3), 261-284.

Rohaan, E. J., Taconis, R., \& Jochems, W. M. G. (2009). Measuring teachers' pedagogical content knowledge in primary technology education. Research in Science and Technological Education, 27(3), $327-338$.

Rohaan, E. J., Taconis, R., \& Jochems, W. M. G. (2010). Reviewing the relations between teachers' knowledge and pupils' attitude in the field of primary technology education. International Journal of Technology and Design Education, 20(1), 15-26.

Schermelleh-Engel, K., Moosbrugger, H., \& Müller, H. (2003). Evaluating the fit of structural equation models: Tests of significance and descriptive goodness-of-fit measures. Methods of Psychological Research Online, 8(2), 23-74.

Van Driel, J. H., Verloop, N., \& De Vos, W. (1998). Developing science teachers' pedagogical content knowledge. Journal of Research in Science Teaching, 35(6), 673-695.

Van Driel, J. H., Beijaard, D., \& Verloop, N. (2001). Professional development and reform in science education: The role of teachers' practical knowledge. Journal of Research in Science Teaching, 38(2), $137-158$.

Verloop, N., Van Driel, J., \& Meijer, P. (2001). Teacher knowledge and the knowledge base of teaching. International Journal of Educational Research, 35(5), 441-461.

Walma van der Molen, J., Wiegerinck, S., \& Rohaan, E. J. (2007). EindrapportageVTB attitude monitor: De ontwikkeling van een attitude-instrument op het gebied van wetenschap en techniek voor leerlingen in het basisonderwijs. [Final report VTB attitude monitor: The development of a attitude instrument in the field of science and technology for pupils in primary education.]. Amsterdam: JWVDM-Advies, training en onderzoek.

Weerden, J. V., Thijssen, J., \& Verhelst, N. (2003). Toetsen techniek in het basisonderwijs. Een onderzoek naar de predictieve validiteit van toetsen techniek in het basisonderwijs. [Tests for technology in primary education. A study on the predictive validaty of tests for technology in primary education]. Arnhem: Citogroep. 